\title{
TAXAS DE DECOMPOSIÇÃO E DE LIBERAÇÃO DE MACRONUTRIENTES DA PALHADA DE AVEIA PRETA EM PLANTIO DIRETO ( $\left.{ }^{1}\right)$
}

\author{
CARLOS ALEXANDRE COSTA CRUSCIOL $\left({ }^{2 *}, 5\right)$; EDEMAR MORO $\left({ }^{2}\right)$; EDUARDO DO VALLE LIMA $\left({ }^{3}\right)$; \\ MARCELO ANDREOTTI $\left({ }^{4}\right)$
}

\begin{abstract}
RESUMO
A palhada das plantas de cobertura mantida sobre o solo em plantio direto é uma reserva importante de nutrientes a ser liberada para as culturas subseqüentes, principalmente em regiões de clima tropical, devido às altas taxas de decomposição dos resíduos. O trabalho foi desenvolvido em condições de campo, durante 1998, no Município de Marechal Cândido Rondon, na Região Oeste do Estado do Paraná. O objetivo deste trabalho foi avaliar a taxa de decomposição e a velocidade de liberação de macronutrientes da palhada de aveia preta, na Região Oeste do Estado do Paraná. O delineamento experimental foi em blocos casualizados, com quatro repetições. As plantas foram manejadas aos trinta dias após a emergência. A persistência de palhada e a liberação de nutrientes do resíduo de aveia preta foram avaliadas $0,13,35$ e 53 dias após a rolagem e dessecação. A taxa de decomposição da aveia foi constante (restando $34 \%$ do teor inicial) e inversamente proporcional à relação $\mathrm{C} / \mathrm{N}$ com valor inicial de 34 e final de 50 . A maior parte do K é liberada logo após o manejo da aveia preta, restando na última coleta apenas $2 \%$ do teor inicial. N, P, Ca e S são liberados de forma gradual, restando na última avaliação, respectivamente, 55\%, $42 \%, 48 \%$ e $47 \%$ da quantidade acumulada. O K seguido do $\mathrm{N}$ são os nutrientes disponibilizados em maior quantidade no solo, atingindo máxima velocidade de liberação entre 10 e 20 dias após o manejo da fitomassa de aveia preta.
\end{abstract}

Palavras-chave: Avena strigosa, resíduo vegetal, degradação de fitomassa, reciclagem de nutrientes.

\section{ABSTRACT \\ DECOMPOSITION RATE AND NUTRIENT RELEASE OF OAT STRAW USED AS MULCHING IN NO-TILL SYSTEM}

\begin{abstract}
Plant residues left on soil surface in no-tillage systems are an important source of nutrients for the following crops, particularly under tropical climate, in which high residue decomposition rates shorten their persistence. The objective of this research work was to evaluate black oat decomposition and release of nutrients. The experiment was carried out during the 1998 cropping season in an experimental area located in Marechal Cândido Rondon, Paraná State, Brazil. A randomized block design with four replications was used. The cover crop was rolled over thirty days after emergence. Persistence and release of nutrients were evaluated at 0, 13, 35 and, 53 days after rolling and desiccation. Decompositon rate of oat residue was constant during this period (remaining $34 \%$ of the initial amount) and inversely proportional to the $\mathrm{C} / \mathrm{N}$ ration that showed an initial value of 34 and a final value of 50 . Most $\mathrm{K}$ was released soon after oat management, remaining only $2 \%$ of the initial content in the last sampling time. $\mathrm{N}, \mathrm{P}, \mathrm{Ca}$ and $\mathrm{S}$ were gradually released, and in the last evaluation the remaining amount of these nutrients was $55 \%, 42 \%, 48 \%$, and $47 \%$ of the total accumulated amount, respectively. Compared to other plant nutrients, $\mathrm{K}$ followed by $\mathrm{N}$ were the nutrients available in higher amount in the soil, reaching maximum release speed between 10 and 20 days after rolling and dessication of black oat.
\end{abstract}

Key words: Avena strigosa, plant residue, phytomass degradation, nutrient cycling.

$\left({ }^{1}\right)$ Recebido para publicação em 26 de maio de 2006 e aceito em 23 de novembro de 2007.

$\left({ }^{2}\right)$ Universidade Estadual Paulista (UNESP), Faculdade de Ciências Agronômicas (FCA), Departamento de Produção Vegetal, Caixa Postal 237, 18603-970 Botucatu (SP). E-mail: crusciol@fca.unesp.br (*) Autor correspondente.

$\left({ }^{3}\right)$ Universidade Federal Rural da Amazônia (UFRA), 66077-530 Belém (PA). E-mail: eduardo.valle@ufra.edu.br

$\left({ }^{4}\right)$ Unesp, Faculdade de Engenharia, Caixa Postal 31, 15385-000 Ilha Solteira (SP). E-mail: dreotti@agr.feis.unesp.br

$\left({ }^{5}\right)$ Com bolsa de produtividade do CNPq. 


\section{INTRODUÇÃO}

Nas regiões de clima tropical, em razão das condições elevadas de temperatura e umidade, a decomposição dos resíduos vegetais ocorre rapidamente, diminuindo a sua persistência sobre o solo, devendo-se, atentar para a quantidade e durabilidade da palhada produzida pela espécie antecedente à cultura principal (Alves et al., 1995). Desse modo, os melhores indicadores da qualidade de uma planta de cobertura são a porcentagem de cobertura do solo, no transcorrer do desenvolvimento, a persistência do resíduo sobre o solo e a capacidade de reciclar nutrientes, notadamente a mobilização de elementos lixiviados ou pouco solúveis, liberando-os gradativamente para a cultura subseqüente.

Uma das principais plantas de cobertura na Região Sul do Brasil e no Estado de São Paulo é a aveia preta (Avena strigosa Schreb.), espécie cultivada em grande extensão no Estado do Paraná como adubo verde de inverno (CALEGARI, 2001). Especificamente na Região Oeste do Paraná, onde o plantio direto representa, aproximadamente, $70 \%$ a $80 \%$ dos sistemas de cultivo. Estima-se que a utilização da aveia preta seja em torno de $30 \%$ em relação às demais espécies usadas nas rotações e sucessões de cultura. Além disso, a aveia preta é muito empregada no cultivo consorciado, com ervilha forrageira, nabo forrageiro e ervilhaca (CALEGARI, 2001).

As principais características que destacam a aveia preta como planta de cobertura são: a rusticidade, a capacidade de perfilhamento, a resistência a pragas e doenças, rapidez na formação da cobertura do solo e a elevada produção de fitomassa, mesmo em solos de baixa fertilidade, bem como a tolerância à seca, em vista do sistema radicular bastante desenvolvido, eficiência na reciclagem de nutrientes, baixa taxa de decomposição dos resíduos comparado às fabáceas, em função da alta relação C / $\mathrm{N}(>30)$ e o elevado efeito alelopático sobre muitas invasoras (DERPSCH e CALEGARI, 1992; Bortolini et al., 2000; Calegari, 2001).

Em plantio direto, poucas foram as pesquisas que visaram estudar a produção de matéria seca e o teor de nutrientes dos resíduos vegetais, logo após o manejo da fitomassa. No entanto, praticamente nenhum estudo acompanhou, em campo, o processo de degradação, assim como a quantidade e a velocidade de elementos liberados às plantas subseqüentes. A aveia preta, mesmo quando cultivada em condição edafoclimática desfavorável (CERETTA et al., 2002), ou quando desenvolvida em cultivo tardio (BERWANGER et al., 2003), apresenta uma produtividade em torno de $4 \mathrm{t} \mathrm{ha}^{-1}$ de matéria seca. Nos meses de março a junho, esse valor pode oscilar de 2 a $7 \mathrm{t} \mathrm{ha}^{-1}$ na floração (CALEgARI, 1998; BerWANGER et al., 2003). Quanto à composição química observada na massa seca da parte aérea da aveia preta (cv. Comum), no florescimento, CALEGARI (1990) constatou $16,5 \mathrm{~g} \mathrm{~kg}^{-1}$; $1,0 \mathrm{~g} \mathrm{~kg}^{-1} ; 16 \mathrm{~g} \mathrm{~kg}^{-1} ; 2,5 \mathrm{~g} \mathrm{~kg}^{-1}$ e $1,7 \mathrm{~g} \mathrm{~kg}^{-1}$ de N, $\mathrm{P}, \mathrm{K}$, $\mathrm{Ca}$ e $\mathrm{Mg}$, nesta ordem. No mesmo estádio de desenvolvimento, média de dois anos, Aita et al. (1994) verificaram acúmulos expressivos de N, P e K iguais a $42,5 \mathrm{~kg} \mathrm{ha}^{-1} ; 10 \mathrm{~kg} \mathrm{ha}^{-1}$ e $89,5 \mathrm{~kg} \mathrm{ha}^{-1}$, respectivamente. Em relação ao $S$, PRIMAVESI et al. (1999), avaliando cultivares de Avena byzantina e Avena sativa quanto ao potencial de ciclagem de nutrientes, produção de grãos e forragem, constataram variação dos teores deste elemento de 0,9 a $2,9 \mathrm{~g} \mathrm{~kg}^{-1}$, dependendo do nível da adubação nitrogenada e do número de cortes.

As plantas de cobertura extraem os nutrientes das camadas mais profundas do solo, por meio do sistema radicular, disponibilizando-os superficialmente, após o manejo da fitomassa e a decomposição pela ação do ambiente. A liberação depende do elemento, e poderá ser rápida e intensa (Rosolem et al., 2003), ou lenta e gradual (PAULETTI, 1999), dependendo, dentre vários fatores, da interação entre a espécie utilizada, o manejo da fitomassa, época de semeadura e de corte, umidade (regime de chuvas), aeração, temperatura, atividade macro e microbiológica, composição química da palha, relação C/N e tipo de solo (OLIVEIRA et al., 1999; BORTOLINI et al., 2000; AlCÂNTARA et al., 2000; Oliveira et al., 2002; PrimAVesi et al., 2002).

O conhecimento do tempo de permanência dos resíduos vegetais e a dinâmica de liberação dos nutrientes são de suma importância, uma vez que o sucesso do plantio direto depende da manutenção de sistemas capazes de gerar quantidades de matéria seca suficientes para manter o solo coberto durante todo o ano (Kliemann et al. 2006). A aveia preta (Família Poaceae) pode ser importante reserva de nutrientes às culturas de verão e ao mesmo tempo manter o solo coberto até o estabelecimento da cultura sucessora.

Este trabalho foi realizado com o objetivo de avaliar a taxa de decomposição e a velocidade de liberação de macronutrientes da palhada de aveia preta, na Região Oeste do Estado do Paraná.

\section{MATERIAL E MÉTODOS}

O trabalho foi desenvolvido em condições de campo, durante o ano de 1998, no Município de Marechal Cândido Rondon, na Região Oeste do Estado do Paraná, latitude $24^{\circ} 31^{\prime} \mathrm{S}$, longitude $54^{\circ} 31^{\prime}$ $\mathrm{W}$ e altitude de $420 \mathrm{~m}$. O clima da região é do tipo Cfa (KöPPEN), classificado como subtropical úmido 
mesotérmico, com verões quentes e geadas pouco freqüentes, com tendência de concentração das chuvas nos meses de verão e sem estação seca definida.

O solo da área experimental é classificado como Latossolo Vermelho Eutroférrico nitossólico (EMBRAPA, 1999), muito argiloso, em que a composição granulométrica possui 108,2 $\mathrm{g} \mathrm{kg}^{-1}$ de areia, 180,6 g $\mathrm{kg}^{-1}$ de silte, $711,2 \mathrm{~g} \mathrm{~kg}^{-1}$ de argila, e os atributos químicos na camada de 0 a $20 \mathrm{~cm}$ iguais a: $\mathrm{pH}$ $\left(\mathrm{CaCl}_{2}\right), 4,9 ;$ M.O., $29 \mathrm{~g} \mathrm{dm}^{-3}$; P (Mehlich 1), $23 \mathrm{mg} \mathrm{dm}^{-}$ 3; $\mathrm{H}+\mathrm{Al}, 58 \mathrm{mmol}_{\mathrm{c}} \mathrm{dm}^{-3} ; \mathrm{K}, \mathrm{Ca}$ e Mg trocáveis, 6, $4 ; 55$ e $20 \mathrm{mmol}_{\mathrm{c}} \mathrm{dm}^{-3}$, respectivamente; $\mathrm{SB}, 81 \mathrm{mmol}_{\mathrm{c}} \mathrm{dm}^{-3}$; CTC, $139 \mathrm{mmol}_{\mathrm{c}} \mathrm{dm}^{-3}$ e V de $58 \%$.

Os tratamentos foram constituídos pelas épocas de coleta da fitomassa da parte aérea da aveia preta após o manejo $(0,13,35$ e 53 dias) e instalado em blocos casualizados, com quatro repetições. A dimensão das parcelas foi de $6 \mathrm{~m}$ de largura e 10 metros de comprimento, totalizando $60 \mathrm{~m}^{2}$.

A semeadura da aveia, cv. Comum, foi efetuada, em 25/7/1998, por meio de cultivo mínimo sobre palhada de feijão, em área mantida sob plantio direto durante quatro anos, cuja emergência ocorreu dez dias após $(4 / 8 / 98)$. Foram semeadas a lanço 90 $\mathrm{kg} \mathrm{ha}^{-1}$ de sementes, visando à produção de fitomassa (Derpsch e Calegari, 1992), e, posteriormente, incorporadas à profundidade de $3 \mathrm{~cm}$, com grade niveladora. Não foi necessária a realização de tratos culturais e não se verificou a ocorrência de pragas e doenças. Também não foram realizadas adubações de semeadura e de cobertura.

Pela necessidade da liberação da área para a implantação da cultura principal na época recomendada e por ter atingindo o fim do perfilhamento, 30 dias após a emergência, o manejo foi efetuado em 3/9/98. A fitomassa da aveia foi manejada com rolo faca, seguido da aplicação de $4 \mathrm{~L}$ ha $^{-1}\left(1.920\right.$ g i.a. ha $\left.{ }^{-1}\right)$ de herbicida comercial à base de glyphosate. Após uma semana (10/9/98), realizouse a semeadura do milho sobre a palhada da aveia preta.

A primeira coleta do material vegetal presente na superfície do solo foi realizada no dia do manejo da aveia preta (0 dias após o manejo - DAM); a segunda coleta em 16/09/98 (13 DAM); a terceira coleta em 08/10/98 (35 DAM) e quarta coleta em 26/ 10/98 (53 DAM).

Para cada repetição, em cada época de coleta, foram feitas amostras compostas formadas por três amostras simples de fitomassa existente em $1 \mathrm{~m}^{2}$. A coleta foi feita manualmente, com auxílio de canivete, retirando-se toda palhada superficial contida na referida área. A amostragem foi realizada diagonalmente, dentro das unidades experimentais, excluindo-se $1 \mathrm{~m}$ de cada extremidade como bordadura.

No campo, os resíduos foram submetidos à pré-limpeza, por meio de peneiras, para a redução da quantidade de solo aderido. Os materiais vegetais foram lavados, sem o emprego de detergente, agitandoos por alguns segundos em água deionizada, em três porções sucessivas e colocados, a seguir, sobre papel absorvente (MALAVOLTA et al., 1997). A lavagem sem a utilização de detergente diminuiu o número de agitações e o tempo de exposição à água, minimizando as perdas de $\mathrm{K}$. As amostras foram acondicionadas em sacos de papel e secadas em estufa com circulação forçada de ar a $60{ }^{\circ} \mathrm{C}$, por 48 horas. A seguir, os materiais foram moídos em moinho tipo Willey e submetidos a análise química, para determinação dos teores de macronutrientes, conforme Malavolta et al. (1997).

A quantidade de macronutrientes acumulada na palhada foi determinada pelo produto da quantidade de matéria seca e os teores de nutrientes do resíduo vegetal. A partir desses valores, determinou-se a taxa de decomposição e a liberação de macronutrientes da palhada de aveia preta.

Os dados obtidos foram submetidos à análises de variância e de regressão polinomial, ajustando-se equações matemáticas.

Aplicando-se a derivada primeira às equações ajustadas aos dados de liberação acumulada de macronutrientes, calcularam-se as taxas diárias de decomposição e de liberação dos nutrientes após o manejo da fitomassa (Rosolem et al., 2003).

\section{RESULTADOS E DISCUSSÃO}

A produção de massa seca da aveia preta após o manejo foi de $2.953 \mathrm{~kg} \mathrm{ha}^{-1}$ (Figura 1). Considerandose que a semeadura da aveia ocorreu tardiamente sem adubação e que o manejo foi realizado no fim do perfilhamento, este valor é considerado expressivo quando comparado aos valores obtidos por CERETTA et al. (2002), de $4.050 \mathrm{~kg} \mathrm{ha}^{-1}$.

Além das questões desfavoráveis descritas acima, ocorreu deficiência hídrica que provocou atraso na germinação e na emergência das plântulas, porém posteriormente compensado com uma precipitação pluvial de $225,8 \mathrm{~mm}$ até o período do manejo. BERWANGER et al. (2003) registraram produção de massa seca variando de 3.200 a $4.000 \mathrm{~kg} \mathrm{ha}^{-1}$, para aveia semeada em época tardia (junho), quando as plantas estavam com $50 \%$ das panículas abertas. 


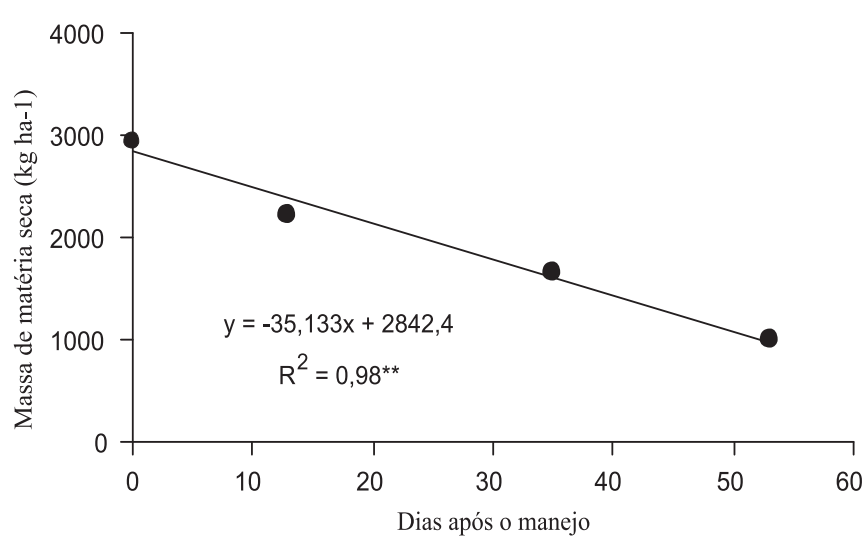

Figura 1. Quantidade de palha de aveia preta sobre o solo em função do tempo após o manejo da fitomassa. ** Significativo a $1 \%$ de probabilidade pelo teste F.

Os resultados da taxa de decomposição da palhada em razão do tempo foram ajustados à função linear, nos quais aos 13,35 e 53 DAM, restavam, respectivamente, $72,2 \% ; 56 \%$ e $33,6 \%$ da quantidade inicial da massa seca (Figura 1). De forma similar, 30 dias após a deposição da massa seca sobre o solo, BORTOLINI et al. (2000) verificaram $52,5 \%$ de resíduo remanescente de aveia preta. Em contrapartida, CERETTA et al. (2002), avaliando a decomposição de resíduos da parte aérea de aveia preta manejada no florescimento, constataram que aos 30 dias após a dessecação o percentual foi menor e igual a $34 \%$.

Quanto à relação $\mathrm{C} / \mathrm{N}$ os dados foram ajustados à função linear positiva (Figura 2). Antes do manejo, a relação $\mathrm{C} / \mathrm{N}$ da aveia era de 34 . Após o manejo os valores ajustados foram 38,44 e 50 para 13,35 e 53 DAM respectivamente. Pelos valores da relação $\mathrm{C} / \mathrm{N}$, observa-se que, embora a massa seca da aveia preta tenha reduzido a $33,6 \%$ aos 53 DAM, ainda é considerada alta, quando comparada aos resíduos vegetais de fabáceas. Esses valores decorrem da alta relação C/N (50 aos 53 DAM) da aveia preta, o que a caracteriza como planta de alta persistência e durabilidade, com baixa taxa de decomposição. Aita e GIACOMINI (2003) observaram que a presença da aveia em consórcios com ervilhaca ocasionou aumento na relação $\mathrm{C} / \mathrm{N}$ da fitomassa e contribuiu para diminuir a velocidade de decomposição dos resíduos culturais, em relação à ervilhaca solteira. A redução na taxa de decomposição é vantajosa, uma vez que, preserva maior quantidade de resíduos culturais sobre o solo, contribuindo para a manutenção da umidade do solo e para sua proteção contra o efeito erosivo da chuva.

De acordo com os dados apresentados na Figura 3, constata-se que ocorreu redução gradual dos teores de macroelementos na palhada remanescente. Esse efeito ocorreu à medida que diminuiu a quantidade do resíduo vegetal sobre o solo (Figura 1).

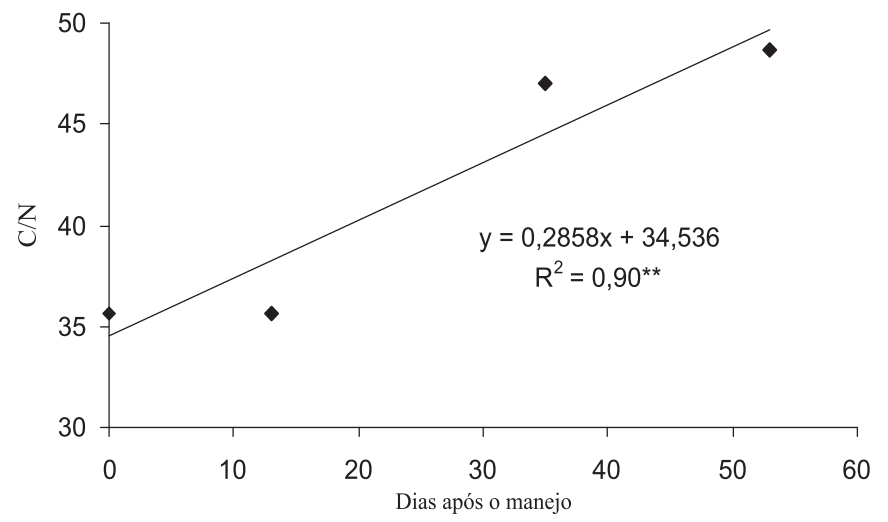

Figura 2. Relação $\mathrm{C} / \mathrm{N}$ da palha de aveia preta em função do tempo após o manejo da fitomassa. ** Significativo a $1 \%$ de probabilidade pelo teste $\mathrm{F}$.

Os dados de N, P, Ca e S foram ajustados a funções lineares, e para os teores de $\mathrm{Mg}$ e $\mathrm{K}$, os dados foram ajustados a equações quadráticas, com tendência de estabilização a partir dos 13 e 35 DAM respectivamente. $\mathrm{O}$ ajuste dos dados de $\mathrm{Mg}$ à função quadrática ocorreu, devido a $70 \%$ deste elemento atuar no vacúolo (MARSCHNER, 1995). Assim, a maior parte do $\mathrm{Mg}$ é rapidamente liberada, uma vez que esta porção não faz parte de constituintes celulares. O restante do $\mathrm{Mg}$ (30\%) é liberado posteriormente de forma gradual, pois faz parte de compostos estruturais das plantas, conferindo aos dados ajuste quadrático.

Quanto ao K, o ajuste dos dados a função quadrática ocorreu pela acentuada liberação inicial deste elemento (aos 13, 35 e 53 DAM a liberação de K foi de $40 \%, 83 \%$ e $98 \%$ respectivamente), com posterior redução em função da baixa quantidade do $\mathrm{K}$ remanescente no tecido vegetal. A rápida liberação de $\mathrm{K}$, na cultura da aveia, também foi observada por Giacomini et al. (2003), a qual ocorre em função do K ser um elemento que não está associado a nenhum componente estrutural do tecido vegetal (MARSCHNER, 1995). Esse elemento não é metabolizado na planta e forma ligações com complexos orgânicos de fácil reversibilidade (Rosolem et al., 2003). Assim, à medida que a parte aérea das plantas de aveia preta inicia o processo de secagem e se degrada, a concentração desse nutriente no tecido diminui drasticamente, pois é facilmente lavado pela água das chuvas (Khatounian, 1999), após o rompimento das membranas plasmáticas (Malavolta et al., 1997).

Ressalta-se ainda que o $\mathrm{K}$, apesar do teor inicial, dentre os macroelementos, ter sido o mais elevado, na última avaliação (53 DAM), estava com teor próximo a zero (Figura 3), ou seja, redução de $98 \%$. Para os demais nutrientes (N, P, Ca, Mg e S), comparando os teores iniciais (0 DAM) com os de 53 DAM, verificaram-se reduções de $40,8 \%, 59,2 \%, 52,4 \%$, $38,1 \%$ e $54 \%$ respectivamente. 

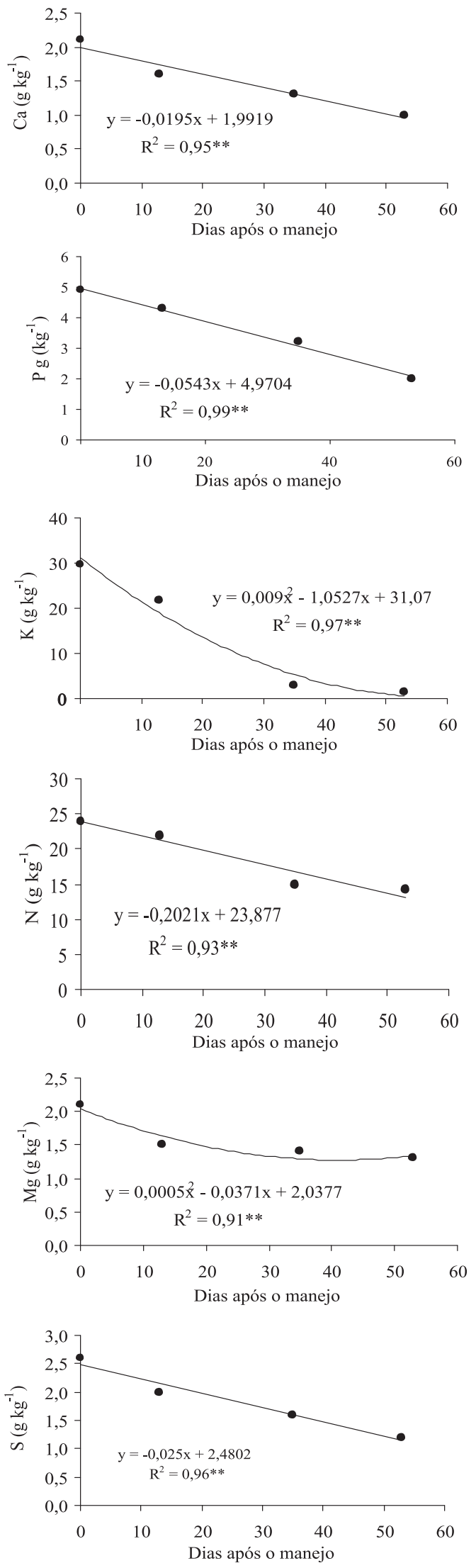

Figura 3. Teores de macronutrientes na palha de aveia preta em função do tempo após o manejo da fitomassa. ** Significativo a $1 \%$ de probabilidade pelo teste F.
No momento do manejo, o acúmulo de N, P e K foi, respectivamente, de $70,1 \mathrm{~kg} \mathrm{ha}^{-1}, 14,7 \mathrm{~kg} \mathrm{ha}^{-1}$ e $88,4 \mathrm{~kg}$ ha $^{-1}$ (Figura 4). Comparando aos resultados obtidos por ArTA et al. (1994), esses valores expressam quantidades substanciais de N, $\mathrm{P}$ e K reciclados pela aveia preta.

Quanto menor a quantidade acumulada do nutriente no resíduo em processo de degradação, maior foi sua quantidade disponibilizada para o solo, ou seja, o comportamento entre essas duas variáveis é inversamente proporcional (Figura 4). As curvas para $\mathrm{N}, \mathrm{K}, \mathrm{Ca}$ e $\mathrm{Mg}$ foram ajustadas a equações quadráticas, cujos pontos de máxima liberação acumulada foram atingidos aos 63, 48, 53 e 50 DAM respectivamente. Assim como para o N, no período de 53 DAM, o ponto de máxima liberação acumulada não foi atingido para $\mathrm{P}$ e S durante o transcorrer do experimento, pois os dados desses dois elementos foram ajustados à função linear (Figura 4).

Para $\mathrm{N}$ o fato de não ter sido atingido a máxima liberação acumulada, durante o transcorrer do experimento, passa a ser de pouca importância, visto que, já aos 35 DAM, mais de 45 $\mathrm{kg} \mathrm{ha}^{-1}$ foi liberado da palha. Esse resultado corrobora aos dados obtidos por CERETTA et al. (2002), quando do cultivo de aveia preta em condições edafoclimáticas favoráveis, em que aos 30 dias após dessecação, a quantidade de $\mathrm{N}$ liberado do resíduo atingiu mais de $33 \mathrm{~kg} \mathrm{ha}^{-1}$. Evidencia-se desta forma que, uma vez fixado em compostos orgânicos, o $\mathrm{N}$ estará sujeito à ciclagem no complexo planta-palha-solo.

Da mesma forma, apesar de não ter atingido o ponto de máxima liberação durante o transcorrer do experimento, o P liberado dos tecidos orgânicos (ligados estruturalmente a moléculas protéicas e em compostos ligados ao transporte de energia), aos $35 \mathrm{e}$ 53 DAM, foram, respectivamente, de 9,4 e $12,7 \mathrm{~kg} \mathrm{ha}^{-1}$, caracterizando a aveia preta como excelente recicladora desse elemento pouco solúvel, como constatado por Aita et al. (1994). Essa quantidade liberada pode ficar disponível tanto para absorção do sistema radicular da cultura subseqüente, quanto para imobilização em compostos minerais de difícil solubilidade (Khatounian, 1999). Contudo, a retenção e a reciclagem desse e de outros nutrientes nas culturas de inverno sempre minimizaram os riscos de perdas por lixiviação e, no caso do $\mathrm{P}$, evitaram que seja alterado para formas menos disponíveis (AitA et al., 1994).

Quanto ao K, a aveia preta disponibilizou, de imediato (13 DAM), valor acima de $30 \mathrm{~kg} \mathrm{ha}^{-1}$, o que corresponde a mais de $35 \mathrm{~kg} \mathrm{ha}^{-1}$ de $\mathrm{K}_{2} \mathrm{O}$, em um período cuja demanda da cultura subseqüente não é alta, podendo, portanto, ser suficiente para o início do seu crescimento. 

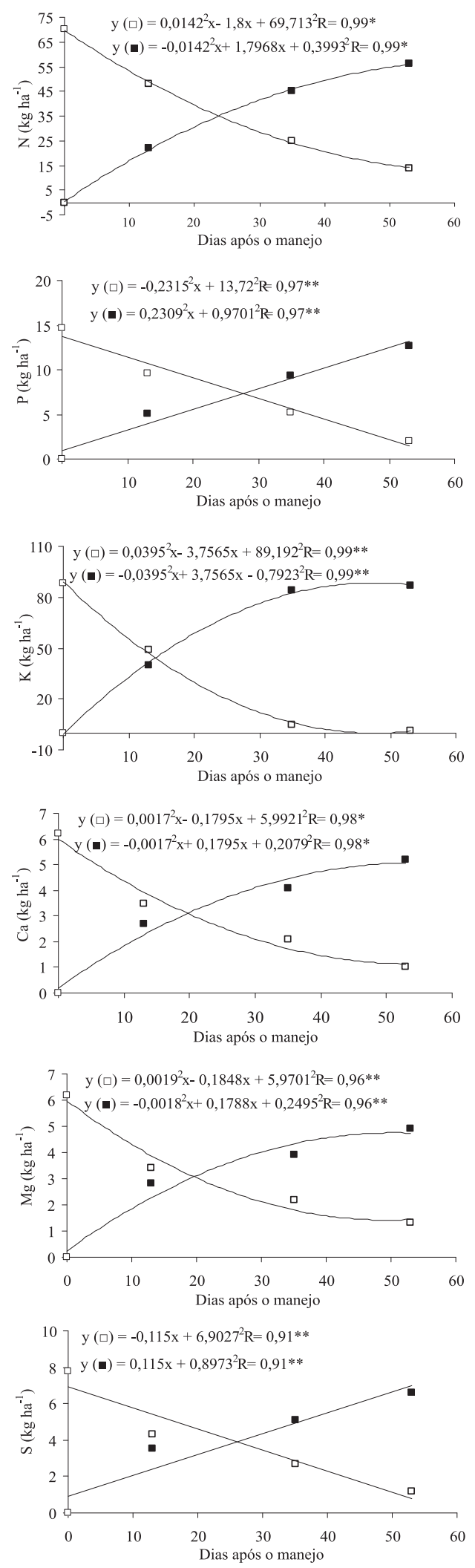

Figura 4. Quantidade de macronutrientes acumulada na palha de aveia preta ( $\square$ ) e liberação acumulada (ם) em função do tempo após o manejo da fitomassa. **, * Significativo, respectivamente, a 1 e $5 \%$ de probabilidade pelo teste $\mathrm{F}$.
Essa mesma observação foi feita por Rosolem et al. (2003). Assim, essa liberação acentuada para o solo confirma a alta reciclagem desse nutriente por espécies da Família Poaceae, favorecendo o processo de rotações e sucessões de culturas.

Os dados da figura 4 estão apresentados na figura 5 na forma de porcentagem, que permite mostrar o ponto de intersecção em que a porcentagem de acúmulo no resíduo foi igual à percentagem de liberação para o solo (Figura 5). Essas duas variáveis se equivaleram, aproximadamente, aos 24 DAM em relação ao N e o P, 20 DAM quanto ao Ca e $\mathrm{Mg}$, e 14 e 23 DAM em relação ao $\mathrm{K}$ e o $\mathrm{S}$ respectivamente. Apenas em relação ao $\mathrm{K}$, a igualdade entre porcentagem acumulada e liberada foi observada na faixa menor de 10 a 20 DAM. Após o manejo da fitomassa, com a palhada seca sobre o solo, há o processo inicial de molhamento pela água das chuvas, com significativa difusão de $\mathrm{K}$, principalmente, dos vacúolos das células da superfície do resíduo, até que a palha fica saturada por água, reduzindo a velocidade de difusão do $K$, que passa a ser proveniente de células mortas do interior do resíduo vegetal (ROSOLEM et al., 2003).

Analisando a taxa de liberação dos nutrientes (Figura 6), verifica-se que a maior velocidade de liberação dos elementos N, K, Ca e Mg ocorreu entre 10 e 20 DAM da fitomassa. Portanto, de modo geral, há uma rápida liberação desses macronutrientes até, aproximadamente, 10 DAM, com redução contínua, a partir de 20 DAM, e posterior tendência à estabilização em valores próximos a zero. Resultado semelhante foi observado por CRUSCIOL et al. (2005) avaliando a taxa de liberação dos nutrientes no nabo forrageiro. Quanto ao $\mathrm{P}$, e $\mathrm{S}$ (Figura 6), no período em que a degradação da palhada foi avaliada, a máxima velocidade de liberação ainda não tinha sido atingida, pois como pode ser constatada na liberação acumulada para o solo (Figura 4), os dados se ajustaram à função linear, assim, não foi possível identificar o ponto de máxima liberação.

As plantas jovens de aveia preta, além da quantidade satisfatória de massa seca produzida (aproximadamente $3 \mathrm{t} \mathrm{ha}^{-1}$ ) caracterizaram-se pelo grande potencial de extrair e reciclar macronutrientes, principalmente, N, P e K, evitando a lixiviação acentuada ou imobilização, tornando-os disponíveis às culturas subseqüentes. Porém, a forma, a quantidade e a velocidade com que cada macroelemento foi liberado neste processo permitem inferir que, para maximizar o aproveitamento desses nutrientes, a implantação da cultura econômica deve ser realizada logo após o manejo da planta de cobertura. Essa mesma sugestão foi feita por CERETTA et al. (2002) no caso do N e, por Rosolem et al. (2003), em relação ao K, pois a aveia preta disponibiliza logo após o manejo grande quantidade desses nutrientes à cultura sucessora. 

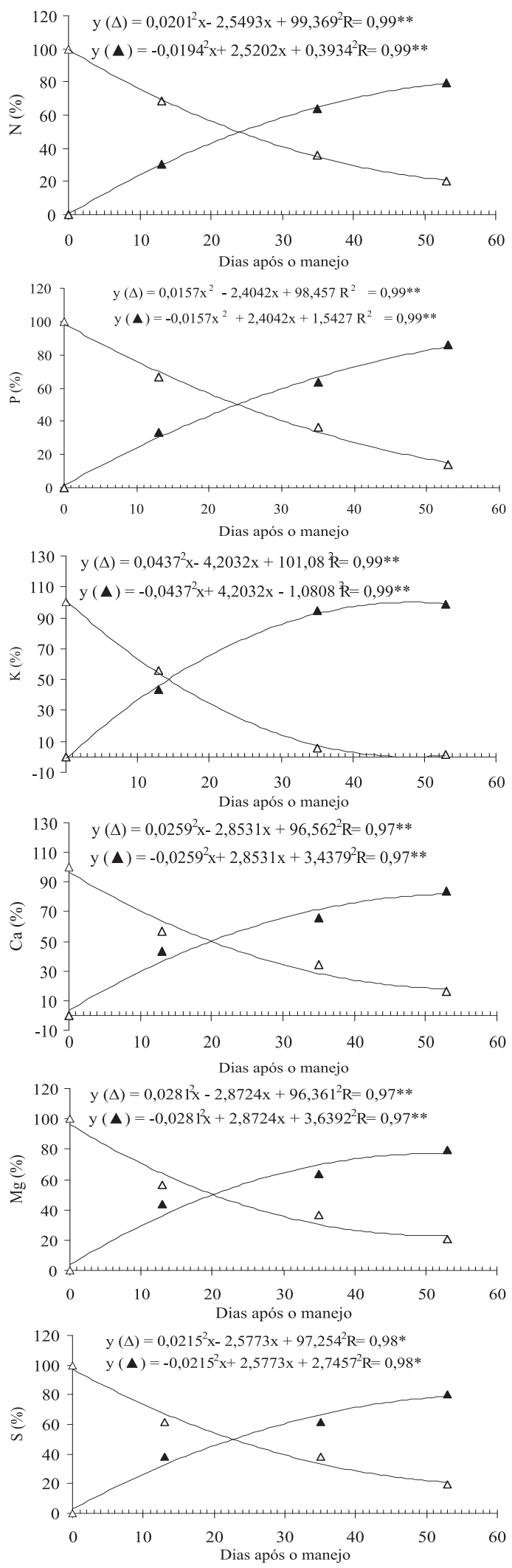

Figura 5. Percentagem de acúmulo de macronutriente na palhada de aveia preta $(\triangle)$ e percentagem de liberação acumulada $(\boldsymbol{\Delta})$ em função do tempo após o manejo da fitomassa. ${ }^{* *}$ * Significativo, respectivamente, a 1 e $5 \%$ de probabilidade pelo teste $\mathrm{F}$.
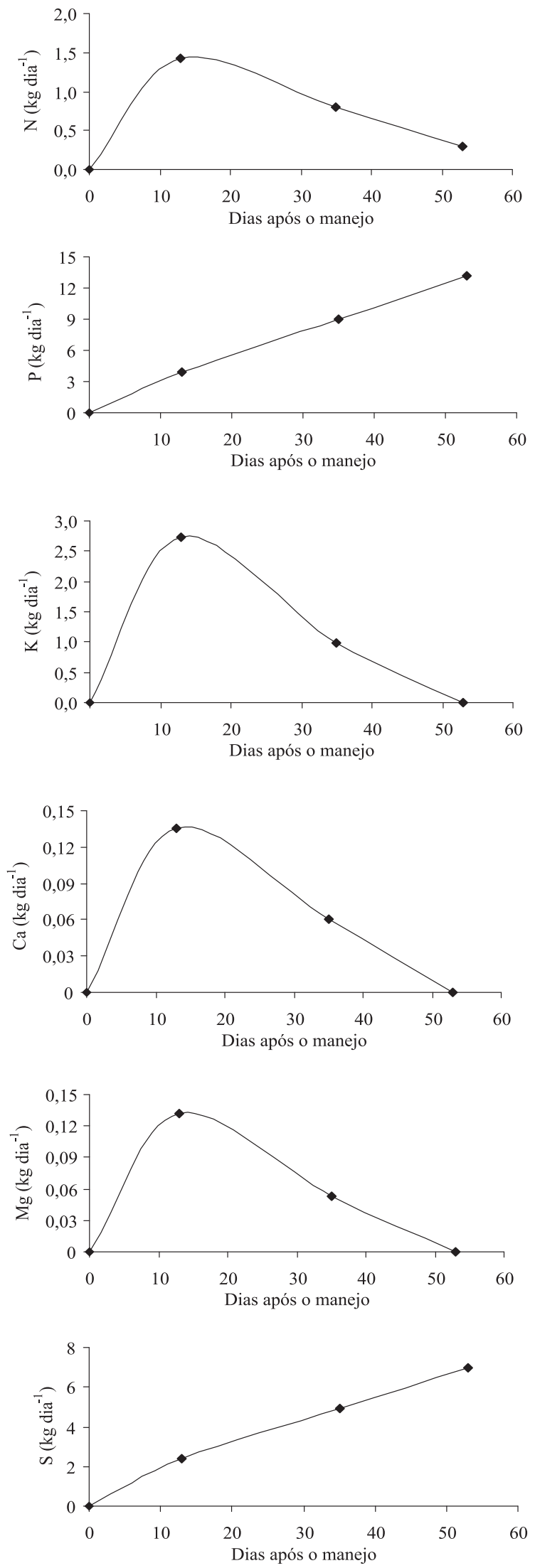

Figura 6. Taxa diária de liberação dos macronutrientes da palhada de aveia preta em função do tempo após o manejo da fitomassa. 


\section{CONCLUSÕES}

1. A taxa de decomposição da aveia foi constante (restando $34 \%$ do teor inicial) e inversamente proporcional à relação $\mathrm{C} / \mathrm{N}$.

2. A maior parte do K é liberada logo após o manejo da aveia preta, restando na última coleta apenas $2 \%$ do teor inicial.

3. O N, P, Ca e S são liberados de forma gradual, restando na última avaliação, respectivamente, $55 \%, 42 \%, 48 \%$ e $47 \%$, da quantidade acumulada.

4. O K seguido do $\mathrm{N}$ são os nutrientes disponibilizados em maior quantidade no solo, atingindo máxima velocidade de liberação entre 10 e 20 dias após o manejo da fitomassa de aveia preta.

\section{REFERÊNCIAS}

AITA, C.;CERETTA, C.A.;THOMAS, A.L.;PAVINATO, A.;BAYER, C. Espécies de inverno como fonte de nitrogênio para o milho no sistema de cultivo mínimo e feijão em plantio direto. Revista Brasileira de Ciência do Solo, Campinas, v. 18, p. 101-108, 1994.

AITA, C.; GIACOMINI, S.J. Decomposição e liberação de nitrogênio de resíduos culturais de plantas de cobertura de solo solteiras e consorciadas. Revista Brasileira de Ciência do Solo, Viçosa, v. 27, p. 601-612, 2003.

ALCÂNTARA, F.A.; FURTINI NETO, A.E.; DE PAULA, M.B.; MESQUITA, H.A.; MUNIZ, J.A. Adubação verde na recuperação da fertilidade de um Latossolo Vermelho-Escuro degradado. Pesquisa Agropecuária Brasileira, Brasília, v. 35, p. 277-288, 2000.

ALVES, A.G.C.; COGO, N.P.; LEVIEN, R. Relações da erosão do solo com a persistência da cobertura vegetal morta. Revista Brasileira de Ciência do Solo, Campinas, v. 19, p. 127-132, 1995.

BERWANGER, A.L.; FACCO, S.; WILDNER, L.P.; DENARDIN, R.B.N.; PANZERA, C.M.; SCHNEIDER, A.M.; PELLE, M. Ecofisiologia de aveia preta (Avena strigosa Schreb.) nas condições da região oeste catarinense. In: CONGRESSO BRASILEIRO DE CIÊNCIA DO SOLO, Ribeirão Preto, 2003. Anais... Ribeirão Preto: Sociedade Brasileira de Ciência do Solo, 2003. CD-ROM

BORTOLINI, C.G.; SILVA, P.R.F.; ARGENTA, G. Efeito de resíduos de plantas jovens de aveia preta em cobertura de solo no crescimento inicial do milho. Pesquisa Agropecuária Gaúcha, Porto Alegre, v. 6, p. 83-88, 2000.

CALEGARI, A. Plantas para adubação verde de inverno no sudoeste do Paraná. Londrina: IAPAR, 1990. 37p. (Boletim Técnico, 35)

CALEGARI, A. Espécies para cobertura de solo. In: DAROLT, M.R. (Ed.). Plantio direto: pequena propriedade sustentável. Londrina: IAPAR, 1998. p.65-94. (Circular, 101)
CALEGARI, A. Rotação de culturas e plantas de cobertura como sustentáculo do sistema de plantio direto. In: CONGRESSO BRASILEIRO DE CIÊNCIA DO SOLO, Londrina, 2001. Anais. Londrina, Sociedade Brasileira de Ciência do Solo, 2001. p.241.

CERETTA, C.A.; BASSO, C.J.; HERBES, M.G.; POLETTO, N.; SILVEIRA, M.J. Produção e decomposição de fitomassa de plantas invernais de cobertura de solo e milho, sob diferentes manejos da adubação nitrogenada. Ciência Rural, Santa Maria, v. 32, p. 49-54, 2002.

CRUSCIOL, C.A.C.; COTTICA, R.L.; LIMA, E.V.; ANDREOTTI, M.; MORO, E.; MARCON, E. Persistência de palhada e liberação de nutrientes do nabo forrageiro no plantio direto. Pesquisa Agropecuária Brasileira, Brasília, v.40, p. 161-168, 2005.

DERPSCH, R.; CALEGARI, A. Plantas para adubação verde de inverno. Londrina, IAPAR, 1992. 80p. (Circular, 73)

EMPRESA BRASILEIRA DE PESQUISA AGROPECUÁRIA EMBRAPA. Centro Nacional de Pesquisa de Solos. Sistema Brasileiro de Classificação de Solos. Rio de Janeiro, 1999. 412p. (EMBRAPA-Solos, Documentos, 15).

GIACOMINI, S.J.; AITA, C.; HÜBNER, A.P.; LUNKES, A.; GUIDINI, E.; AMARAL, E. B. Liberação de fósforo e potássio durante a decomposição de resíduos culturais em plantio direto. Pesquisa Agropecuária Brasileira, Brasília, v. 38, n. 9, p. 1097-1104, set. 2003.

KHATOUNIAN, C.A. O manejo da fertilidade em sistemas de produção. In: CASTRO FILHO, C.; MUZILLIO, O. (Ed.). Uso e manejo dos solos de baixa aptidão agrícola. Londrina: IAPAR, 1999. p.179-221. (Circular, 108)

KLIEMANN, H. J.; BRAZ, A. J. P. B.; SILVEIRA, P. M. Taxas de decomposição de resíduos de espécies de cobertura em latossolo vermelho distroférrico. Pesquisa Agropecuária Tropical, v. 36, p. 21-28, 2006.

MALAVOLTA, E.; VITTI, G.C.; OLIVEIRA, S.A. Avaliação do estado nutricional de plantas: princípios e aplicações. Piracicaba: Potafos, 1997. 308p.

MARSCHNER, H. Mineral nutrition of higher plants. London: Academic Press, 1995. 889p.

OLIVEIRA, M.W.; TRIVELIN, P.C.O.; PENATTI, C.P.; PICCOLO, M.C. Decomposição de nutrientes da palhada de cana-de-açúcar em campo. Pesquisa Agropecuária Brasileira, Brasília, v. 34, p. 2359-2362, 1999.

OLIVEIRA, T.K.; CARVALHO, G.J.; MORAES, R.N.S. Plantas de cobertura e seus efeitos sobre o feijoeiro em plantio direto. Pesquisa Agropecuária Brasileira, Brasília, v. 37, p. 1079-1087, 2002.

PAULETTI, V. A importância da palhada e da atividade biológica na fertilidade do solo. In: CURSO SOBRE ASPECTOS BÁSICOS DE FERTILIDADE E MICROBIOLOGIA DO SOLO EM PLANTIO DIRETO, Cruz Alta, 1999. Palestras... Passo Fundo: Aldeia Norte, 1999. p.56-66. 
PRIMAVESI, A.C.; PRIMAVESI, O.; GODOY, R. Extração de nutrientes e eficiência nutricional de cultivares de aveia, em relação ao nitrogênio e à intensidades de corte. Scientia Agricola, Piracicaba, v. 56, n. 3, p. 613-620, 1999.

PRIMAVESI, O.; PRIMAVESI, A.C.; ARMELIN, M.J.A. Qualidade mineral e degrabilidade potencial de adubos verdes conduzidos sobre Latossolos, na região tropical de São Carlos, SP, Brasil. Revista de Agricultura, Piracicaba, v. 77, p. 89-102, 2002.
ROSOLEM, C.A.; CALONEGO, J.C.; FOLONI, J.S.S. Lixiviação de potássio da palhada de espécies de cobertura de solo de acordo com a quantidade de chuva aplicada. Revista Brasileira de Ciência do Solo, Viçosa, v. 27, p.355-362, 2003. 